\title{
Clinical updates of approaches for biopsy of pulmonary lesions based on systematic review
}

\author{
Chuan-Jiang Deng ${ }^{\dagger}$, Fu-Qiang Dai ${ }^{\dagger}$, Kai Qian, Qun-You Tan, Ru-Wen Wang, Bo Deng ${ }^{*}$ and Jing-Hai Zhou ${ }^{*}$
}

\begin{abstract}
Background: Convenient approaches for accurate biopsy are extremely important to the diagnosis of lung cancer. We aimed to systematically review the clinical updates and development trends of approaches for biopsy, i.e., CT-guided PTNB (Percutaneous Transthoracic Needle Biopsy), ENB (Electromagnetic Navigation Bronchoscopy), EBUS-TBNA (Endobroncheal Ultrasonography-Transbronchial Needle Aspiration), mediastinoscopy and CTC (Circulating Tumor Cell).

Methods: Medline and manual searches were performed. We identified the relevant studies, assessed study eligibility, evaluated methodological quality, and summarized diagnostic yields and complications regarding CT-guided PTNB (22 citations), ENB(31 citations), EBUS-TBNA(66 citations), Mediastinoscopy(15 citations) and CTC (19 citations), respectively.

Results: The overall sensitivity and specificity of CT-guided PTNB were reported to be $92.52 \% \pm 3.14 \%$ and $97.98 \% \pm 3.28 \%$, respectively. The top two complications of CT-guided PTNB was pneumothorax (946/4170:22.69\%) and hemorrhage (138/ 1949:7.08\%). The detection rate of lung cancer by ENB increased gradually to $79.79 \% \pm 15.34 \%$ with pneumothorax as the top one complication (86/1648:5.2\%). Detection rate of EBUS-TBNA was $86.06 \% \pm 9.70 \%$ with the top three complications, i. e., hemorrhage (53/8662:0.61\%), pneumothorax (46/12432:0.37\%) and infection (34/11250:0.30\%). The detection rate of mediastinoscopy gradually increased to $92.77 \% \pm 3.99 \%$ with . hoarseness as the refractory complication (4/2137:0.19\%). Sensitivity and specificity of CTCs detection by using PCR (Polymerase Chain Reaction) were reported to be $78.81 \% \pm 14.72 \%$ and $90.88 \% \pm 0.53 \%$, respectively.

Conclusion: The biopsy approaches should be chosen considering a variety of location and situation of lesions. CTguided PTNB is effective to reach lung parenchyma, however, diagnostic accuracy and incidence of complications may be impacted by lesion size or needle path length. ENB has an advantage for biopsy of smaller and deeper lesions in lung parenchyma. ENB plus EBUS imaging can further improve the detection rate of lesion in lung parenchyma. EBUSTBNA is relatively safer and mediastinoscopy provides more tissue acquisition and better diagnostic yield of $4 \mathrm{R}$ and 7 th lymph node. CTC detection can be considered for adjuvant diagnosis.
\end{abstract}

Keywords: Lung cancer, Percutaneous transthoracic needle biopsy, Electromagnetic navigation bronchoscopy, Endobroncheal ultrasonography, Circulating tumor cell

\footnotetext{
*Correspondence: dengbo@tmmu.edu.cn; zhzhlu1993@aliyun.com

${ }^{+}$Chuan-Jiang Deng and Fu-Qiang Dai contributed equally to this work. Department of Thoracic Surgery, Institute of Surgery Research, Daping Hospital, Army Medical University, Chongqing 400042, People's Republic of China
}

(c) The Author(s). 2018 Open Access This article is distributed under the terms of the Creative Commons Attribution 4.0 International License (http://creativecommons.org/licenses/by/4.0/), which permits unrestricted use, distribution, and reproduction in any medium, provided you give appropriate credit to the original author(s) and the source, provide a link to the Creative Commons license, and indicate if changes were made. The Creative Commons Public Domain Dedication waiver (http://creativecommons.org/publicdomain/zero/1.0/) applies to the data made available in this article, unless otherwise stated. 


\section{Background}

Lung cancer is the most frequently diagnosed cancer and continues to be the leading cause of cancer mortality among both males and females [1]. The 5-year survival rate of lung cancer is only $18 \%$, largely due to late-stage diagnosis [1]. Thus, early diagnosis is especially critical to improve long-term survival. Biopsy is important for identification and confirmation of lung cancer. In clinical practice, conventional flexible bronchoscopy is supposed to be difficult for biopsy of small lesions in lung parenchyma or mediastinum. Therefore, we focused on the following approaches for biopsy according to a variety of lesion location in lung parenchyma, i.e., CT-guided PTNB(Percutaneous Transthoracic Needle Biopsy), ENB (Electromagnetic Navigation Bronchoscopy), EBUS-TBNA (Endobroncheal Ultrasonography-Transbronchial Needle Aspitation) and mediastinoscopy. Furthermore, the studies regarding liquid biopsies, e.g., CTC (Circulating Tumor Cell) detection are timely and hot, and warrant to be systematically reviewed.

Therefore, we evaluated the published studies in the last 20 years which focused on CT-guided PTNB, ENB, EBUS-TBNA, mediastinoscopy and CTC, aiming to reveal the clinical updates, development trends, detection rates and complications.

\section{Methods}

We used systematic review to identify relevant studies, assess study eligibility, evaluate methodological quality, and summarize findings regarding postoperative clinical outcomes. Medline and manual searches were performed by investigators CJD and FQD independently and jointly to identify all published articles in English journals from January 1, 2000 to November 9, 2017 that addressed the issues regarding detection of lung cancers by using $\mathrm{CT}$-guided PTNB, ENB, EBUS-TBNA, mediastinoscopy and CTCs, respectively. The Medline search was done on PubMed (http://www.ncbi.nlm.nih.gov). The search strategies and yielded citations were shown in Tables 1 and 2, respectively. Investigators CJD and FQD performed the actual search and data abstraction.

\section{Data abstraction}

From the eligible articles, investigators CJD and FQD reviewed the following information, i.e., PMID, year of publication, study design, number of patients, average age of patients, nodules size and location, operation time, biomarkers for detection, diagnostic sensitivity, relative complication morbidity, treatment of complications, outcome and follow-up period.

\section{Statistical analysis}

The association between detection rate of ENB and nodule size, number of cases, operation time, average age of patients, sex, and mean distance of the lesions from the pleura was performed using Pearson's correlation analysis. The impact of nodule location on detection rate of ENB was analyzed by using ANOVA analysis. The association between morbidity of pneumothorax following ENB and nodule size was performed using Pearson's correlation analysis. The analyses were performed using SPSS Version 11.0 software for Windows (SPSS, Inc., Chicago, IL, USA). $P<0.05$ (two-sided) was considered to indicate a statistically significant difference.

\section{Results \\ CT-guided PTNB: Biopsy of lesion in lung parenchyma mapped on $\mathrm{CT}$ images}

In last 20 years, the overall sensitivity, specificity, and accuracy of CT-guided PTNB were 92.52 $\pm 3.14 \%$, $97.98 \pm 3.28 \%$, and $92.28 \% \pm 5.40 \%$, respectively. The top two complications of CT-guided PTNB were pneumothorax (1111/ 4822:23.04\%) and hemorrhage (287/3503:8.19\%), respectively. Two cases with severe complications were reported $[2,3]$. Bronchial artery embolization was performed in one patient due to massive hemoptysis [3]. The other one suffered from cardiopulmonary arrest leading to death [2].

Diagnostic accuracy and incidence of complications seemed to be decreased [3-5] and increased [2-9], respectively, by smaller lesion size or longer needle path length $(P<0.05)$.

Table 1 Data sources and searches regarding Clinical updates of approaches for biopsy

\begin{tabular}{|c|c|c|c|c|c|}
\hline Methods & Search term & Period & Additional filters & $\begin{array}{l}\text { Citation number } \\
\text { after filtration }\end{array}$ & $\begin{array}{l}\text { Citation number after } \\
\text { Manual verification }\end{array}$ \\
\hline CT-guided PTNB & $\begin{array}{l}\text { ct guided transthoracic needle biopsy[All Fields] } \\
\text { AND lung neoplasms[MeSH Terms] }\end{array}$ & $\begin{array}{l}\text { From January 1, } 2000 \\
\text { To November 9, } 2017\end{array}$ & $\begin{array}{l}\text { English, humans } \\
\text { without review }\end{array}$ & 106 & 22 \\
\hline ENB & $\begin{array}{l}\text { 'electromagnetic navigation } \\
\text { bronchoscopy (ENB)'[All Fields] }\end{array}$ & $\begin{array}{l}\text { From January 1, } 2000 \\
\text { To November 9, } 2017\end{array}$ & $\begin{array}{l}\text { English, humans } \\
\text { without review }\end{array}$ & 91 & 31 \\
\hline EBUS-TBNA & $\begin{array}{l}\text { EBUS[All Fields] AND "lung neoplasms" } \\
\text { [MeSH Terms] }\end{array}$ & $\begin{array}{l}\text { From January 1, } 2000 \\
\text { To November 9, } 2017\end{array}$ & $\begin{array}{l}\text { English, humans } \\
\text { without review }\end{array}$ & 613 & 66 \\
\hline Mediastinoscopy & $\begin{array}{l}\text { Mediastinoscopy[Mesh Terms] } \\
\text { AND "lung neoplasms"[MeSH Terms] }\end{array}$ & $\begin{array}{l}\text { From January 1, } 2000 \\
\text { To November 9, } 2017\end{array}$ & $\begin{array}{l}\text { English, humans } \\
\text { without review }\end{array}$ & 333 & 15 \\
\hline CTC & $\begin{array}{l}\text { 'Neoplastic Cells, Circulating'[Mesh Terms] } \\
\text { AND "lung neoplasms"[MeSH Terms] }\end{array}$ & $\begin{array}{l}\text { From January 1, } 2000 \\
\text { To November 9, } 2017\end{array}$ & $\begin{array}{l}\text { English, humans } \\
\text { without review }\end{array}$ & 459 & 19 \\
\hline
\end{tabular}


Table 2 Information of yielded citations regarding approaches for biopsy

\begin{tabular}{|c|c|c|c|c|c|}
\hline PMID & Year & Method & Corresponding author & Cases & Diagnostic sensitivity \\
\hline $28,415,930$ & 2017 & CT-guided PTNB & Feride Fatma Go"rgu"lu" & 65 & $90.80 \%$ \\
\hline $28,063,634$ & 2016 & CT-guided PTNB & C. Fontaine-Delaruelle & 929 & N/A \\
\hline $26,980,483$ & 2016 & CT-guided PTNB & Mickey Sachdeva & 203 & N/A \\
\hline $26,397,325$ & 2015 & CT-guided PTNB & M. Petranovic & 52 & N/A \\
\hline $26,110,775$ & 2015 & CT-guided PTNB & Wen Yang & 311 & $77 \%$ \\
\hline $25,903,714$ & 2015 & CT-guided PTNB & Matthew Koslow & 181 & $94.40 \%$ \\
\hline $25,816,042$ & 2015 & CT-guided PTNB & Fabio Pagni & N/A & $97.60 \%$ \\
\hline $25,662,328$ & 2015 & CT-guided PTNB & Anna Galluzzo & 23 & $87 \%$ \\
\hline $25,569,025$ & 2015 & CT-guided PTNB & Sébastien Couraud & 980 & $90 \%$ \\
\hline $25,051,977$ & 2014 & CT-guided PTNB & Tingyang $\mathrm{Hu}$ & 341 & N/A \\
\hline $24,581,458$ & 2014 & CT-guided PTNB & Jeffrey S. Klein & 32 & N/A \\
\hline $24,475,839$ & 2014 & CT-guided PTNB & Chang Min Park & 1108 & $97 \%$ \\
\hline $25,763,320$ & 2014 & CT-guided PTNB & Sanjay Piplani & 74 & $95.94 \%$ \\
\hline $23,510,132$ & 2013 & CT-guided PTNB & Antonio Bugalho & 123 & N/A \\
\hline $23,079,048$ & 2013 & CT-guided PTNB & Yi-Ping Zhuang & 102 & $96.10 \%$ \\
\hline $22,951,610$ & 2012 & CT-guided PTNB & Ragulin IuA & 107 & N/A \\
\hline $22,124,475$ & 2012 & CT-guided PTNB & Yeun-Chung Chang & 55 & N/A \\
\hline $21,537,657$ & 2012 & CT-guided PTNB & $\mathrm{Lu} \mathrm{CH}$ & 89 & $91.50 \%$ \\
\hline $21,098,171$ & 2010 & CT-guided PTNB & Hye Sun Hwang & 27 & $94 \%$ \\
\hline $15,246,522$ & 2004 & CT-guided PTNB & Ohno Y & N/A & $96.90 \%$ \\
\hline $14,595,149$ & 2003 & CT-guided PTNB & Stephen T. Kee & 846 & $96 \%$ \\
\hline $14,595,149$ & 2003 & CT-guided PTNB & Stephen T. Kee & 846 & $92 \%$ \\
\hline $12,118,196$ & 2002 & CT-guided PTNB & Adnan Yilmaz & 294 & $88 \%$ \\
\hline $28,410,635$ & 2017 & ENB & Christopher W. Towe & 341 & N/A \\
\hline $27,623,421$ & 2017 & ENB & Michael Chacey & 31 & $96.80 \%$ \\
\hline $28,459,951$ & 2017 & ENB & Kongjia Luo & 24 & $100.00 \%$ \\
\hline $28,449,489$ & 2017 & ENB & Hiran C. Fernando & 17 & $79.00 \%$ \\
\hline $28,399,830$ & 2017 & ENB & Erik E. Folch & 1000 & N/A \\
\hline $26,944,363$ & 2016 & ENB & Mohammed Al-Jaghbeer & 92 & $60.00 \%$ \\
\hline $27,157,054$ & 2016 & ENB & Arjun Pennathur & 29 & $100.00 \%$ \\
\hline $27,424,820$ & 2016 & ENB & Fumihiro Asano & 932 & $71.00 \%$ \\
\hline $25,849,298$ & 2015 & ENB & Demet Karnak & 44 & $72.80 \%$ \\
\hline $25,590,477$ & 2015 & ENB & Mark R. Bowling & 107 & $73.60 \%$ \\
\hline $24,739,685$ & 2014 & ENB & Nima Nabavizadeh & 31 & N/A \\
\hline $24,401,166$ & 2014 & ENB & Gregoire Gex & 971 & $64.90 \%$ \\
\hline $23,440,066$ & 2013 & ENB & Demet Karnak & 76 & $89.50 \%$ \\
\hline $24,323,803$ & 2013 & ENB & Rana S Hoda & 40 & $94.00 \%$ \\
\hline $23,649,436$ & 2013 & ENB & M. Patricia Rivera & 932 & $71.00 \%$ \\
\hline $22,391,437$ & 2012 & ENB & B.Lamprecht & 112 & $83.90 \%$ \\
\hline $22,277,964$ & 2012 & ENB & Daryl Phillip Pearlstein & 104 & $85.00 \%$ \\
\hline $23,207,529$ & 2012 & ENB & Christopher R Dale & 100 & N/A \\
\hline $23,207,349$ & 2012 & ENB & Kyle R. Brownback & 55 & $74.50 \%$ \\
\hline $23,207,460$ & 2012 & ENB & Kurt W. Jensen & 92 & $65.00 \%$ \\
\hline $23,169,081$ & 2011 & ENB & Amit K. Mahajan & 49 & $77.00 \%$ \\
\hline
\end{tabular}


Table 2 Information of yielded citations regarding approaches for biopsy (Continued)

\begin{tabular}{|c|c|c|c|c|c|}
\hline PMID & Year & Method & Corresponding author & Cases & Diagnostic sensitivity \\
\hline $20,850,809$ & 2010 & ENB & Carsten Schroeder & 52 & $N / A$ \\
\hline $20,802,352$ & 2010 & ENB & Felix J. F. Herth & 25 & $80.00 \%$ \\
\hline $20,435,658$ & 2010 & ENB & Luis M. Seijo & 51 & $67.00 \%$ \\
\hline $19,648,733$ & 2010 & ENB & med. Ralf Eberhardt & 54 & $75.50 \%$ \\
\hline $19,546,519$ & 2009 & ENB & Jean-Michel Vergnon & 54 & $71.40 \%$ \\
\hline $17,400,670$ & 2007 & ENB & Armin Ernst & 92 & $67.00 \%$ \\
\hline $17,360,724$ & 2007 & ENB & C-H. Marquette & 40 & $62.50 \%$ \\
\hline $17,532,538$ & 2007 & ENB & Motoko Tachihara & 94 & $62.50 \%$ \\
\hline $17,379,850$ & 2007 & ENB & Armin Ernst & 120 & $59.00 \%$ \\
\hline $16,873,767$ & 2006 & ENB & Thomas R. Gildea & 60 & $74.00 \%$ \\
\hline $29,054,229$ & 2017 & EBUS-TBNA & Chen-Yoshikawa & 413 & N/A \\
\hline $27,710,975$ & 2016 & EBUS-TBNA & Fumihiro Tanaka & 20 & $75.00 \%$ \\
\hline $27,435,209$ & 2016 & EBUS-TBNA & João Pedro Steinhauser Motta & 84 & $61.00 \%$ \\
\hline $27,409,724$ & 2015 & EBUS-TBNA & Whittney A. Warren & 333 & $98.86 \%$ \\
\hline $27,150,855$ & 2016 & EBUS-TBNA & Sang-Won Um & 161 & $94.00 \%$ \\
\hline $26,656,954$ & 2015 & EBUS-TBNA & Baijiang Zhang & 114 & $81.20 \%$ \\
\hline $26,545,094$ & 2015 & EBUS-TBNA & Wen-Chien Cheng & 2527 & N/A \\
\hline $26,386,084$ & 2015 & EBUS-TBNA & Massimo Barberis & 291 & $95.53 \%$ \\
\hline $26,176,519$ & 2015 & EBUS-TBNA & Sebastián Fernández-Bussy & 145 & $91.17 \%$ \\
\hline $25,611,227$ & 2015 & EBUS-TBNA & Sang-Won Um & 138 & $92.90 \%$ \\
\hline $25,584,815$ & 2014 & EBUS-TBNA & Roberto F. Casal & 220 & N/A \\
\hline $25,170,748$ & 2014 & EBUS-TBNA & Andrew R.L. Medford & 70 & $90.00 \%$ \\
\hline $25,149,044$ & 2014 & EBUS-TBNA & Masato Shingyoji & 113 & $88.40 \%$ \\
\hline $24,930,616$ & 2014 & EBUS-TBNA & Masahide Oki & 150 & $89 \%$ \\
\hline $24,853,017$ & 2014 & EBUS-TBNA & Yasushi Murakami & 100 & $97.00 \%$ \\
\hline $24,419,182$ & 2013 & EBUS-TBNA & Paul F. Clementsen & 76 & $88.16 \%$ \\
\hline $24,340,058$ & 2013 & EBUS-TBNA & Takayuki Shiroyama & 178 & $73.60 \%$ \\
\hline $24,238,520$ & 2014 & EBUS-TBNA & Zhao H & 66 & $89.40 \%$ \\
\hline $24,172,712$ & 2013 & EBUS-TBNA & Kang HJ & 74 & $93.20 \%$ \\
\hline $24,125,976$ & 2013 & EBUS-TBNA & Ozgül MA & 40 & $94.70 \%$ \\
\hline $24,079,724$ & 2013 & EBUS-TBNA & Lonny Yarmus & 85 & $100.00 \%$ \\
\hline $24,075,565$ & 2013 & EBUS-TBNA & Yinin $\mathrm{Hu}$ & 231 & $90.00 \%$ \\
\hline $23,994,976$ & 2013 & EBUS-TBNA & Sang-Won Um & 42 & $95.30 \%$ \\
\hline $23,953,728$ & 2013 & EBUS-TBNA & Konstantinos Syrigos & 981 & $76.20 \%$ \\
\hline $23,723,003$ & 2013 & EBUS-TBNA & Guo-liang Xu & 128 & $93.00 \%$ \\
\hline $23,663,438$ & 2013 & EBUS-TBNA & Fumihiro Asano & 7345 & N/A \\
\hline $23,639,784$ & 2013 & EBUS-TBNA & Riccardo Inchingolo & 662 & $77.00 \%$ \\
\hline $23,609,248$ & 2013 & EBUS-TBNA & Christian B. Gindesgaard & 116 & $87.00 \%$ \\
\hline $23,609,243$ & 2013 & EBUS-TBNA & Hammad A. Bhatti & 13 & $94.00 \%$ \\
\hline $23,571,718$ & 2013 & EBUS-TBNA & Masahide Oki & 108 & $88.00 \%$ \\
\hline $23,549,813$ & 2013 & EBUS-TBNA & Sang-Won Um & 37 & $86.40 \%$ \\
\hline $23,245,441$ & 2012 & EBUS-TBNA & Kazuhiro Yasufuku & 438 & $96.50 \%$ \\
\hline $23,117,878$ & 2014 & EBUS-TBNA & George A. Eapen & 1317 & N/A \\
\hline $24,632,834$ & 2014 & EBUS-TBNA & Sang-Won Um & 44 & $79.00 \%$ \\
\hline
\end{tabular}


Table 2 Information of yielded citations regarding approaches for biopsy (Continued)

\begin{tabular}{|c|c|c|c|c|c|}
\hline PMID & Year & Method & Corresponding author & Cases & Diagnostic sensitivity \\
\hline $24,603,902$ & 2013 & EBUS-TBNA & Moishe Liberman & 161 & $72.00 \%$ \\
\hline $22,219,613$ & 2012 & EBUS-TBNA & Sang-Won Um & 151 & $91.60 \%$ \\
\hline $22,154,791$ & 2011 & EBUS-TBNA & Benjamin E. Lee & 73 & $95.00 \%$ \\
\hline $21,963,329$ & 2011 & EBUS-TBNA & Kazuhiro Yasufuku & 153 & $81.00 \%$ \\
\hline $21,792,077$ & 2011 & EBUS-TBNA & Sam M. Janes & 161 & $87.00 \%$ \\
\hline $21,718,857$ & 2011 & EBUS-TBNA & Alexander Chen & 50 & $81.00 \%$ \\
\hline $21,651,742$ & 2011 & EBUS-TBNA & Shahab Nozohoo & 243 & $66.00 \%$ \\
\hline $21,592,457$ & 2010 & EBUS-TBNA & Kazuhiro Yasufuku & 450 & $93.10 \%$ \\
\hline $20,819,667$ & 2010 & EBUS-TBNA & Tian Q & 33 & $69.70 \%$ \\
\hline $20,740,503$ & 2010 & EBUS-TBNA & Qing Kay Li & 47 & $89.50 \%$ \\
\hline $20,609,781$ & 2010 & EBUS-TBNA & Kazuhiro Yasufuku & N/A & $96.40 \%$ \\
\hline $20,372,904$ & 2010 & EBUS-TBNA & J. Eckardt & 308 & $72.00 \%$ \\
\hline $20,138,390$ & 2010 & EBUS-TBNA & Bin Hwangbo & 126 & $97.20 \%$ \\
\hline $20,037,856$ & 2010 & EBUS-TBNA & Sökücü SN & N/A & $88.20 \%$ \\
\hline $20,022,759$ & 2010 & EBUS-TBNA & Artur Szlubowski & 61 & $67.00 \%$ \\
\hline $19,890,836$ & 2009 & EBUS-TBNA & Wei Sun & 64 & $88.90 \%$ \\
\hline $19,789,210$ & 2009 & EBUS-TBNA & Andrew RL Medford & 54 & $89.00 \%$ \\
\hline $19,699,917$ & 2009 & EBUS-TBNA & Sebastien Gilbert & 172 & $86.60 \%$ \\
\hline $19,590,457$ & 2009 & EBUS-TBNA & Armin Ernst & N/A & $91.00 \%$ \\
\hline $19,502,074$ & 2009 & EBUS-TBNA & Henrik Ømark Petersen & 157 & $85.00 \%$ \\
\hline $19,447,014$ & 2009 & EBUS-TBNA & Devanand Anantham & N/A & $90.00 \%$ \\
\hline $19,371,395$ & 2008 & EBUS-TBNA & David Fielding & 68 & $94.00 \%$ \\
\hline $19,068,672$ & 2008 & EBUS-TBNA & Marie-Paule Jacob-Ampuero & 48 & $77.00 \%$ \\
\hline $18,952,453$ & 2009 & EBUS-TBNA & Jarosław Kuzdza & 226 & $89.00 \%$ \\
\hline $18,263,680$ & 2007 & EBUS-TBNA & Armin Ernst & 100 & $89.00 \%$ \\
\hline $17,916,175$ & 2008 & EBUS-TBNA & Mariko Siyue Koh & 38 & $62.00 \%$ \\
\hline $17,379,850$ & 2006 & EBUS-TBNA & Armin Erns & 120 & $69.00 \%$ \\
\hline $17,035,455$ & 2007 & EBUS-TBNA & Meng-Chih Lin & 151 & $73.80 \%$ \\
\hline $16,963,667$ & 2006 & EBUS-TBNA & Takehiko Fujisawa & 102 & $92.30 \%$ \\
\hline $16,807,262$ & 2005 & EBUS-TBNA & F.J.F. Herth & 100 & $92.30 \%$ \\
\hline $16,171,897$ & 2005 & EBUS-TBNA & Takehiko Fujisawa & 105 & $94.60 \%$ \\
\hline $27,385,137$ & 2016 & Mediastinoscopy & Necati $C_{s}$ itak & 261 & $96.00 \%$ \\
\hline $27,385,137$ & 2016 & Mediastinoscopy & Necati $C_{s}$ itak & 187 & $95.00 \%$ \\
\hline $24,751,152$ & 2014 & Mediastinoscopy & Benjamin Wei & 721 & $87.10 \%$ \\
\hline $23,778,084$ & 2013 & Mediastinoscopy & Akif Turna & 344 & $92.20 \%$ \\
\hline $23,778,084$ & 2013 & Mediastinoscopy & Akif Turna & 89 & $96.60 \%$ \\
\hline $23,008,924$ & 2012 & Mediastinoscopy & Ashutosh Chauhan & 39 & $87.50 \%$ \\
\hline $22,219,461$ & 2012 & Mediastinoscopy & Carme Obiolsa & 221 & $95.00 \%$ \\
\hline $21,601,176$ & 2011 & Mediastinoscopy & Young Mog Shim & 521 & $95.90 \%$ \\
\hline $20,417,780$ & 2010 & Mediastinoscopy & Yaron Shargall & 104 & $98.90 \%$ \\
\hline $20,417,780$ & 2010 & Mediastinoscopy & Yaron Shargall & 396 & $97.20 \%$ \\
\hline $18,520,794$ & 2008 & Mediastinoscopy & Armin Ernst & 66 & $78.00 \%$ \\
\hline $18,687,697$ & 2008 & Mediastinoscopy & Elias A. Karfis & 139 & $88.40 \%$ \\
\hline $18,054,494$ & 2007 & Mediastinoscopy & Gunda Leschber & 377 & $87.90 \%$ \\
\hline
\end{tabular}


Table 2 Information of yielded citations regarding approaches for biopsy (Continued)

\begin{tabular}{|c|c|c|c|c|c|}
\hline PMID & Year & Method & Corresponding author & Cases & Diagnostic sensitivity \\
\hline $12,842,542$ & 2003 & Mediastinoscopy & Jèrôme Mouroux & 154 & $98.00 \%$ \\
\hline $12,683,545$ & 2003 & Mediastinoscopy & Didier Lardinois & 195 & $95.60 \%$ \\
\hline $11,321,666$ & 2001 & Mediastinoscopy & Reidar Grénman & 249 & $84.30 \%$ \\
\hline $26,913,536$ & 2016 & CTC & María Jose Serrano & 56 & $51.80 \%$ \\
\hline $26,951,195$ & 2016 & CTC & Noriyoshi Sawabata & 23 & $30.40 \%$ \\
\hline $27,206,795$ & 2016 & CTC & Binlei Liu & 40 & $55.00 \%$ \\
\hline $27,206,795$ & 2016 & CTC & Binlei Liu & 40 & $75.00 \%$ \\
\hline $25,996,878$ & 2015 & CTC & Wei Li & 169 & $23.70 \%$ \\
\hline $25,678,504$ & 2014 & CTC & Mario Santini & 16 & $89.00 \%$ \\
\hline $23,861,795$ & 2013 & CTC & Viswam S. Nair & 43 & $60.47 \%$ \\
\hline $21,098,695$ & 2011 & CTC & Paul Hofman & 208 & $49.00 \%$ \\
\hline $21,215,651$ & 2011 & CTC & Noriyoshi Sawabata & 75 & $69.33 \%$ \\
\hline $21,683,606$ & 2011 & $\mathrm{CTC}$ & Renato Franco & 45 & $23.90 \%$ \\
\hline $21,128,227$ & 2010 & CTC & Paul Hofman & 210 & $39.00 \%$ \\
\hline $21,128,227$ & 2010 & CTC & Paul Hofman & 210 & $50.00 \%$ \\
\hline $20,471,712$ & 2010 & CTC & Chul-Woo Kim & 61 & $42.60 \%$ \\
\hline $20,471,712$ & 2010 & CTC & Chul-Woo Kim & 61 & $36.10 \%$ \\
\hline $19,887,487$ & 2009 & CTC & Fumihiro Tanaka & 125 & $71.00 \%$ \\
\hline $18,514,066$ & 2008 & CTC & Yan-hui Yin & 134 & $84.30 \%$ \\
\hline $18,606,477$ & 2008 & CTC & Shang-mian Yie & 67 & $38.80 \%$ \\
\hline $17,554,991$ & 2007 & CTC & Noriyoshi Sawabata & 9 & $11.10 \%$ \\
\hline $16,642,481$ & 2006 & CTC & Inn-Wen Chong & 100 & $90.00 \%$ \\
\hline $15,801,980$ & 2005 & CTC & Katharina Pachmann & 29 & $86.21 \%$ \\
\hline $12,167,790$ & 2002 & CTC & Michio Ogawa & 57 & $38.60 \%$ \\
\hline
\end{tabular}

\section{ENB: Biopsy of lesion in lung parenchyma and} mediastinal area

The detection rate of lung cancer by ENB increased gradually (Fig. 1a) and was recently reported to be $96.8 \%$ [10]. There seemed to be no significant correlation between detection rate and number of cases, average age of patients, sex, nodule size, lobar location of nodule, mean distance from pleura to nodule and operation time. As shown in Fig. 1b, pneumothorax was the top one complication following ENB (86/1648:5.2\%). In 86 pneumothorax cases, 34 cases $(34 / 86)$ were administrated with closed drainage [10-21], and one case (1/86) was managed with manual aspiration and observation [19]. The other 51 cases with mild pneumothorax were discharged for rehabilitation. Intriguingly, the incidence of pneumothorax was significantly negatively correlated with nodule size $(R=-0.512, P=0.018$, Fig. 1c). The three hemorrhage cases were observed carefully without further intervention and were discharged for rehabilitation $[16,22]$. Three cases of respiratory failure were reported without detailed depiction [16]. There were no ENB related death [10-30]. ENB plus EBUS imaging seemed to yield a higher detection rate as compared with sole use of ENB (59\% vs. $88 \%$ [20] and $71.42 \%$ vs. $73.07 \%$ [11]). Surprisingly, studies combining fluoroscopy with ENB to confirm navigation success reported lower diagnostic yields (56.3 vs. $69.2 \%$ without fluoroscopy, $p=0.006$ ) [31].

\section{EBUS-TBNA: Biopsy of lesion in subcarinal and bilateral hilar area}

The detection rate of lung node by EBUS-TBNA remained to be $86.06 \pm 9.70 \%$. The diagnostic sensitivity, specificity, accuracy, positive predictive value and negative predictive value of EBUS-TBNA for the mediastinal staging of lung cancer were $85.48 \% \pm 12.89 \%, 99.09 \% \pm 3.15 \%$, $92.88 \% \pm 4.99 \%, \quad 98.70 \% \pm 3.03 \%, \quad 83.03 \% \pm 15.46 \%$, respectively. As shown in Fig. 2a, the top three complications following EBUS-TBNA were hemorrhage (53/ 8662:0.61\%), pneumothorax (46/12432:0.37\%) and infection (34/11250:0.30\%), respectively. Four hemorrhage cases were administrated with further intervention with one perioperative death. The other 49 cases with mild hemorrhage were discharged for rehabilitation [32, 33]. In 46 pneumothorax cases, nine cases $(9 / 46)$ and 37 cases (37/46) were administrated with closed drainage and 


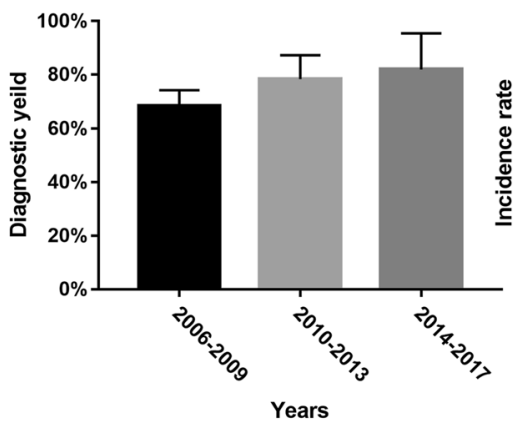

A

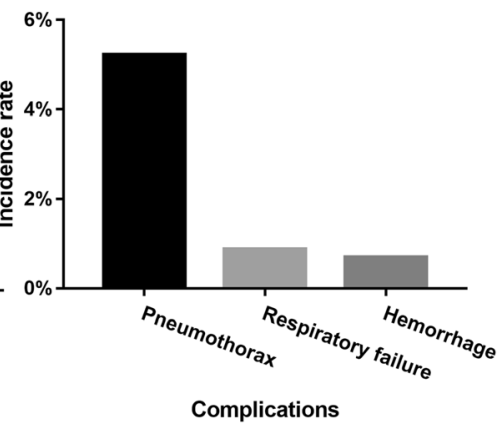

B

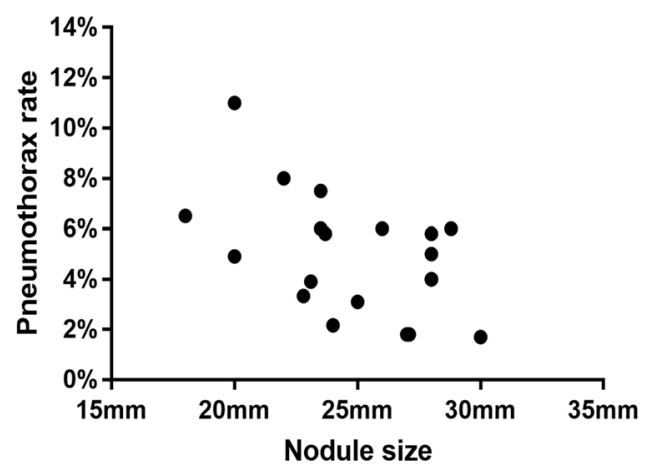

C

Fig. 1 Analysis of clinical points regarding ENB. a Correlation between detection rate and publication time showing the detection rate increased gradually. b Pneumothorax was the top one complication following ENB (86/1648:5.2\%). c The morbidity of pneumothorax was significantly negatively correlated with nodule size $(R=-0.512, P=0.018)$

conservative treatment, respectively [32-35]. Perioperative mortality was relatively low (4/11189:0.04\%). Besides the above mentioned one case died of severe hemorrhage, there was one case died of cerebral infarction and two unexplained deaths $[32,33,36]$.

\section{Mediastinoscopy: Biopsy of the lesion or lymph node in the vicinity of the trachea, the subcarinal and the bronchi area}

The detection rate of lung cancer by mediastinoscopy increased slightly (Fig. 2b) which was reported to be $96 \%$ in recent years [37]. The diagnostic sensitivity, specificity, accuracy, positive predictive value and negative predictive value of mediastinoscopy for the mediastinal staging of lung cancer were $82.83 \% \pm 10.63 \%$, $100 \%$, $93.98 \% \pm 4.68 \%, 100 \%, 87.64 \% \pm 13.00 \%$, respectively. Intriguingly, the positive rates of $4^{\text {th }} \mathrm{R}(91.5 \% \pm 9.35 \%)$ and 7 th $(80.56 \% \pm 19.47 \%)$ lymph node were significantly higher than others $(P=0.03)$ (Fig. 2c). As shown in Fig. $2 \mathrm{~d}$, hoarseness $(67 / 4387: 1.53 \%)$ was the top one complication following mediastinoscopy. Among the abovementioned 67 cases with hoarseness, nine cases (9/67) suffered from permanent hoarseness, two cases $(2 / 67)$ recovered partially by vocal cord medialization and six cases $(6 / 67)$ recovered within a few months [37-45]. Perioperative mortality was relatively low (4/2137: $0.19 \%)$. The death causes among three cases were aortic laceration, stroke, and cardiac arrest, respectively, and one case die of unexplained cause [46].

\section{CTC: Biopsies of tumor cells shed from solid tumor lesion into peripheral blood}

The mean sensitivities of a variety of methods to detect CTC remained to be $63.05 \%$. As shown in Fig. 3a, sensitivity of PCR seemed to be highest $(78.81 \pm 14.72 \%)$. Sensitivity of Density-gradient, ISET and Magnetic bead seemed to be higher than $60 \%(71.32 \% \pm 2.8 \%$, $67.75 \% \pm 21.22 \%$ and $67.85 \% \pm 25.24 \%$, respectively). Specificity of ISET, PCR and Cell search was relatively high $(100 \%, 90.88 \pm 0.53 \%$ and $94.33 \% \pm 9.82 \%$, respectively). There was no published data regarding specificity of Magnetic bead and density-gradient.

Intriguingly, there are a variety of biomarker combination for CTCs identification by using PCR yielding different sensitivities. As shown in Fig. 3b, the sensitivity of Multimarker assay seemed to be highest (90\%). Besides, the sensitivity of the combination of TSA-9, KRT-19, Pre-proGRP was satisfactory (84.3\%). 

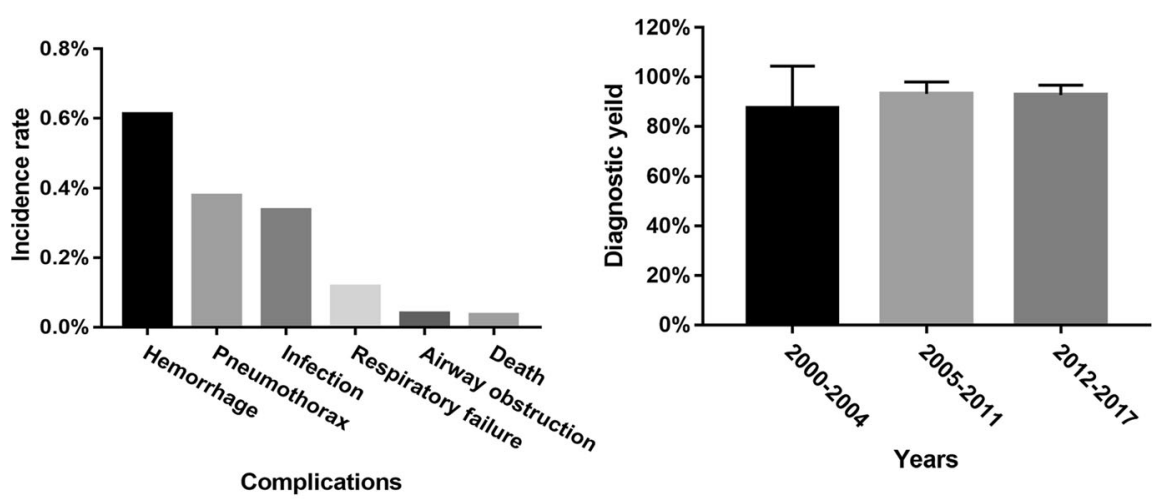

A

B
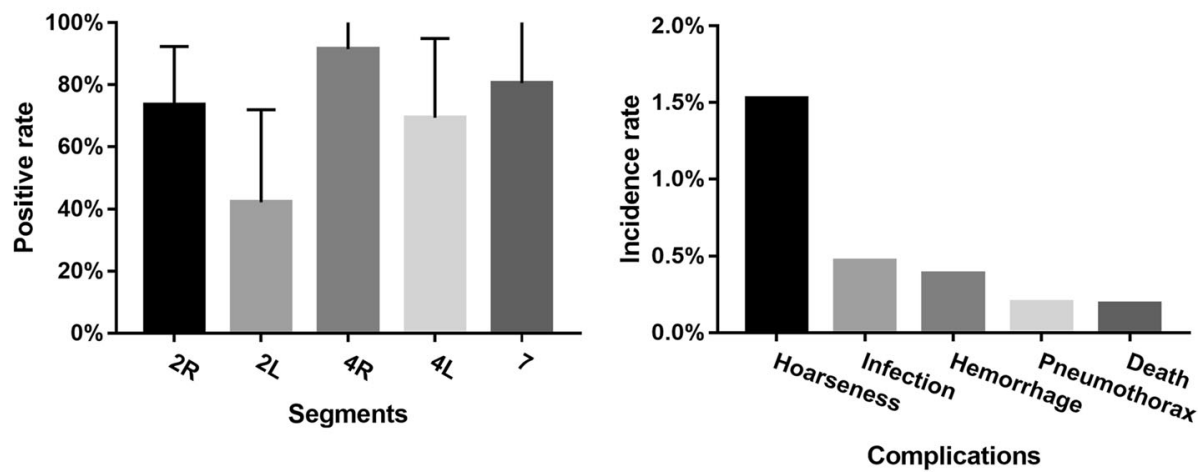

C

D

Fig. 2 Analysis of clinical points regarding EBUS-TBNA and mediastinoscopy. a The top three complications following EBUS-TBNA were hemorrhage (53/8662:0.61\%), pneumothorax (46/12432:0.37\%) and infection (34/1 1250:0.30\%), respectively. b The detection rate by using mediastinoscopy increased slightly. $\mathbf{c}$ The positive rate of $4^{\text {th }} \mathrm{R}(91.5 \% \pm 9.35 \%)$ and 7 th $(80.56 \% \pm 19.47 \%)$ lymph node by using mediastinoscopy were significantly higher than others $(P<0.05)$. d Hoarseness $(67 / 4387: 1.53 \%)$ was the top one complication following mediastinoscopy

\section{Discussion}

Considering the exquisite anatomy of the mediastinum, hilar and lung parenchyma, the equipment and technique, e.g., percutaneous lung biopsy, ENB, EBUS-TBNA, and Mediastinoscopy developed quickly. Furthermore, liquid biopsy, e.g., CTC detection has been introduced and a few pilot studies regarding early diagnosis of lung cancer have been published [47-65]. According to application in specific location and situation, we systemic reviewed clinical updates of these approaches focusing on development trends, detection rate and complications .

CT-guided PTNB is regarded as an effective and feasible procedure to detect a difficult nodule with advantage of accurate positioning and high detection accuracy. Nevertheless, once the lesion diameter is less than $2 \mathrm{~cm}$ or the needle path length is more than $8 \mathrm{~cm}$, the detection rate will drop dramatically [4]. In addition, the lesions in the vicinity of mediastinum vessels are challengers to clinicians with regards to safety. Currently, ENB is developed for biopsy of the lesions in deep lung parenchyma or mediastinum.
ENB is recommended in patients with lesions in lung parenchyma difficult to reach with conventional bronchoscopy or CT-guided PTNB. The detection rate of ENB increased gradually probably due to improvement of software and hardware. Eberhardt et al. [20] found nodule location has been noted to be an important factor in diagnostic yield, e.g., the yields from the lower lobes were significantly lower $(29 \% ; p=0.01)$. However, Jensen et al. [22] found lobar location of nodule did not affect the diagnostic yield $(p=0.59)$. Therefore, we systematically analyzed the results of six studies mentioning detection rate and nodule location [14, 20, 22, 27, 29, 66], and found that there seemed to be no association between them $(p=0.433)$. The highest incidence of complication is pneumothorax (5.2\%). However, pneumothorax following ENB was reported to be unrelated with age or sex [16], accordant with our results. Intriguingly, the incidence of pneumothorax seemed to be significantly negatively correlated with nodule size, probably due to difficulties varying with the size. Additionally, 


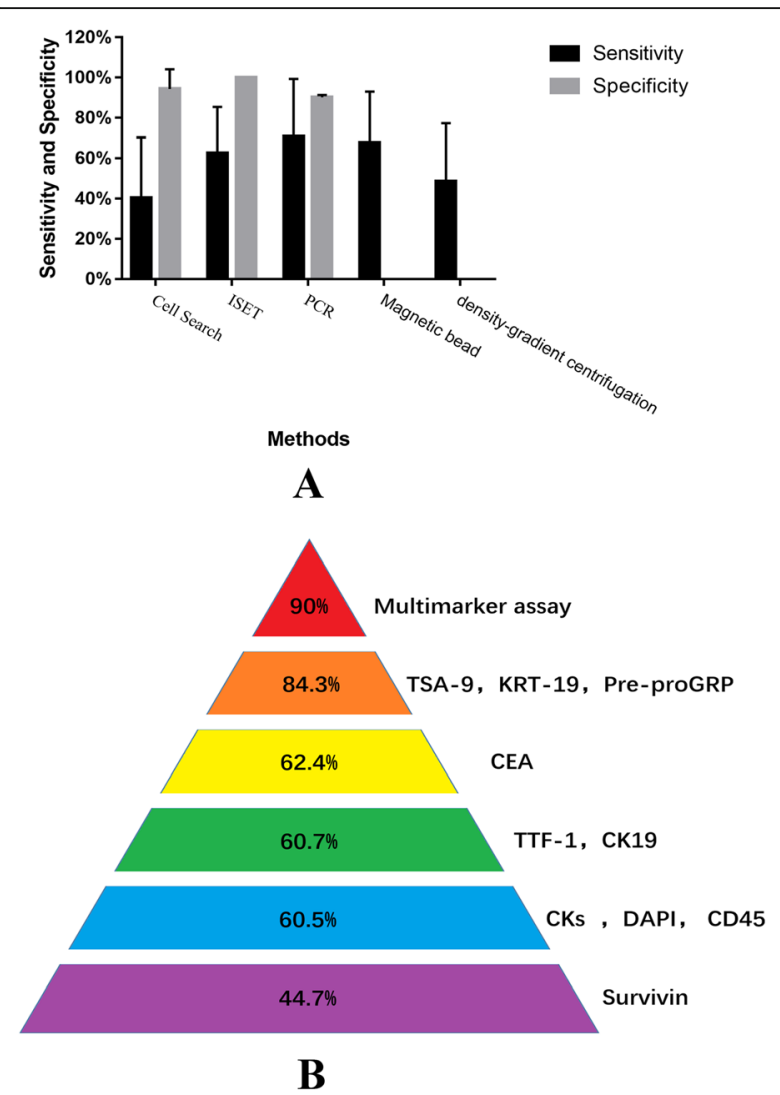

Fig. 3 Analysis of clinical points regarding CTCs. a Sensitivity of PCR seemed to be highest $(78.81 \pm 14.72 \%)$. Specificity of ISET, PCR and Cell search was relatively high $(100 \%, 90.88 \pm 0.53 \%$ and $94.33 \pm 9.82 \%)$. b Sensitivity of Multimarker assay seemed to be highest(90\%) including 17 target genes: AGR2, CEACAM5, MMP11, STRN3, CEACAM6, COL5A2, AMPH, CEACAM7, ABCC3, THY1, COL6A3, ENO1, PNN, SCFD1, KDELR3, KIAA0391, TACSTD1

there was no reported ENB associated death, proving that ENB is relatively safe.

Empirically, EBUS-TBNA is suitable for biopsy of lesion in subcarinal and bilateral hilar area. EBUS-TBNA is also well utilized in the peripheral area with radial probe EBUS and in conjunction with ENB. As EBUS-TBNA has relatively high false negative rates, especially at station $4 \mathrm{R}$ or 7 lymph node, mediastinoscopy is still required for patients with suspicious nodal disease in these stations [67]. Cytological samples are usually taken by EBUS-TBNA, however, larger histological tissue samples are possible to obtain by mediastinoscopy.

Mediastinoscopy is always recognized as the gold standard for surgical staging of lung cancer which is suitable for biopsy in the vicinity of the trachea, the subcarinal and the bronchi area. Especially, the positive rate of station $4 R^{\text {th }}(91.5 \pm 9.35 \%)$ and 7 th $(80.56 \pm 19.47 \%)$ lymph node were significantly higher than other stations (Fig. 2c). Nevertheless, as mediastinoscopy is an invasive approach, the incidences of complications are relatively remarkable.
CTC is a kind of liquid biopsies of tumor cells shed from solid tumor lesions (primary foci and metastases) into peripheral blood. Although the mean sensitivities of CTC detection were not satisfactory, the convenience of this non-invasive method seems to be incomparable. Sensitivity of PCR remained to be highest $(78.81 \% \pm 14.72 \%)$ as compared with other methods. Intriguingly, the sensitivities of PCR varies with combined biomarkers. Expectedly, the sensitivity of combination of multimarkers assay is highest (90\%). Furthermore, the specificity of the three methods, i.e., ISET, PCR and Cell search, was relatively high $(100 \%, 90.88 \% \pm 0.53 \%$ and $94.33 \% \pm 9.82 \%$, respectively). Currently, CTC can be used as an auxiliary diagnostic method to provide a higher detection rate.

\section{Conclusions}

The biopsy approaches should be chosen according to a variety of location and situation of lesions. CT-guided PTNB is regarded as an effective and feasible procedure for biopsy in lung parenchyma, however, diagnostic accuracy and incidence of complications may be impacted by lesion size or needle path length. ENB has an advantage for biopsy of smaller and deeper lesions in lung parenchyma. ENB plus EBUS imaging can further improve the detection rate. EBUS-TBNA and mediastinoscopy can be recommended for the biopsy in lower and upper mediastinum, respectively. The former is relatively safer and the latter provides more tissue acquisition and better diagnostic yield of $4 \mathrm{R}$ and 7 th lymph node. CTC detection can be considered for adjuvant diagnosis.

\section{Abbreviations}

CTC: Circulating tumor cell; EBUS-TBNA: Endobroncheal UltrasonographyTransbronchial Needle Aspitation; ENB: Electromagnetic navigation bronchoscopy; PCR: Polymerase chain reaction; PTNB: Percutaneous transthoracic needle biopsy

\section{Acknowledgements}

We'd appreciated Drs. Mingzhou Guo, Riitta Kaarteenaho and J. Francis Turner for valuable comments which improves our manuscript greatly.

\section{Funding}

This study was supported by grants from the National Natural Science Foundations of China (NSFC) (No. 81101782 and 81572285), and National Natural Science Foundation of Chongqing City (No.cstc2018jcyjAX0592).

\section{Availability of data and materials}

The dataset was searched on PubMed (http://www.ncbi.nlm.nih.gov). The search strategies and yielded citations were shown in Tables 1 and 2, respectively.

\section{Authors' contributions}

$\mathrm{BD}$ conceived and designed the study. CJD and FQD searched the data and performed data analysis. CJD wrote the paper. BD, JHZ, KQ, QYT and RWW reviewed and edited the manuscript. All authors read and approved the manuscript.

Ethics approval and consent to participate Not applicable 


\section{Consent for publication}

Not applicable

\section{Competing interests}

The authors declare that they have no competing interests.

\section{Publisher's Note}

Springer Nature remains neutral with regard to jurisdictional claims in published maps and institutional affiliations.

Received: 21 June 2018 Accepted: 23 August 2018 Published online: 03 September 2018

\section{References}

1. Siegel RL, Miller KD, Jemal A. Cancer statistics, 2018. CA Cancer J Clin. 2018; 68(1):7-30.

2. Geraghty PR, et al. CT-guided transthoracic needle aspiration biopsy of pulmonary nodules: needle size and pneumothorax rate. Radiology. 2003; 229(2):475-81.

3. Lee $\mathrm{SM}$, et al. C-arm cone-beam CT-guided percutaneous transthoracic needle biopsy of lung nodules: clinical experience in 1108 patients. Radiology. 2014;271(1):291-300

4. Ohno Y, et al. Transthoracic CT-guided biopsy with multiplanar reconstruction image improves diagnostic accuracy of solitary pulmonary nodules. Eur J Radiol. 2004;51(2):160-8.

5. Yang W, et al. Diagnostic accuracy of CT-guided transthoracic needle biopsy for solitary pulmonary nodules. PLoS One. 2015;10(6):e0131373.

6. Gorgulu FF, et al. Computed tomography-guided transthoracic biopsy: factors influencing diagnostic and complication rates. J Int Med Res. 2017; 45(2):808-15.

7. Otto $\mathrm{S}$, et al. Predictors of technical success and rate of complications of image-guided percutaneous transthoracic lung needle biopsy of pulmonary tumors. PLoS One. 2015;10(4):e0124947.

8. Sachdeva $\mathrm{M}$, et al. Complications and yield of computed tomographyguided transthoracic Core needle biopsy of lung nodules at a high-volume academic Center in an Endemic Coccidioidomycosis Area. Lung. 2016; 194(3):379-85.

9. Jaconi M, et al. C-arm cone-beam CT-guided transthoracic lung core needle biopsy as a standard diagnostic tool: an observational study. Medicine (Baltimore). 2015;94(12):e698.

10. Mukherjee S, Chacey M. Diagnostic yield of electromagnetic navigation bronchoscopy using a curved-tip catheter to aid in the diagnosis of pulmonary lesions. J Bronchology Interv Pulmonol. 2017:24(1):35-9.

11. Ozgul G, et al. Efficacy and safety of electromagnetic navigation bronchoscopy with or without radial endobronchial ultrasound for peripheral lung lesions. Endosc Ultrasound. 2016;5(3):189-95.

12. Mahajan AK, et al. Electromagnetic navigational bronchoscopy: an effective and safe approach to diagnose peripheral lung lesions unreachable by conventional bronchoscopy in high-risk patients. J Bronchology Interv Pulmonol. 2011;18(2):133-7.

13. Schroeder C, Hejal R, Linden PA. Coil spring fiducial markers placed safely using navigation bronchoscopy in inoperable patients allows accurate delivery of CyberKnife stereotactic radiosurgery. J Thorac Cardiovasc Surg. 2010;140(5):1137-42.

14. Eberhardt $\mathrm{R}$, et al. Electromagnetic navigation diagnostic bronchoscopy in peripheral lung lesions. Chest. 2007;131(6):1800-5.

15. Pearlstein DP, et al. Electromagnetic navigation bronchoscopy performed by thoracic surgeons: one center's early success. Ann Thorac Surg. 2012;93(3): 944-9. discussion 949-50

16. Towe CW, et al. Severe chronic obstructive pulmonary disease is not associated with complications after navigational bronchoscopy procedures. Ann Thorac Surg. 2017;104(1):290-5.

17. Makris $D$, et al. Electromagnetic navigation diagnostic bronchoscopy for small peripheral lung lesions. Eur Respir J. 2007;29(6):1187-92.

18. Bertoletti $L$, et al. Accuracy and feasibility of electromagnetic navigated bronchoscopy under nitrous oxide sedation for pulmonary peripheral opacities: an outpatient study. Respiration. 2009;78(3):293-300.

19. Chee A, et al. Diagnostic utility of peripheral endobronchial ultrasound with electromagnetic navigation bronchoscopy in peripheral lung nodules. Respirology. 2013;18(5):784-9.
20. Eberhardt R, et al. Multimodality bronchoscopic diagnosis of peripheral lung lesions: a randomized controlled trial. Am J Respir Crit Care Med. 2007; 176(1):36-41.

21. Bowling MR, et al. The effect of general anesthesia versus intravenous sedation on diagnostic yield and success in electromagnetic navigation bronchoscopy. J Bronchology Interv Pulmonol. 2015;22(1):5-13.

22. Jensen $\mathrm{KW}$, et al. Multicenter experience with electromagnetic navigation bronchoscopy for the diagnosis of pulmonary nodules. J Bronchology Intery Pulmonol. 2012;19(3):195-9.

23. Eberhardt $\mathrm{R}$, et al. Comparison of suction catheter versus forceps biopsy for sampling of solitary pulmonary nodules guided by electromagnetic navigational bronchoscopy. Respiration. 2010;79(1):54-60.

24. Dale $C R$, et al. Navigational bronchoscopy with biopsy versus computed tomography-guided biopsy for the diagnosis of a solitary pulmonary nodule: a cost-consequences analysis. J Bronchology Interv Pulmonol. 2012; 19(4):294-303

25. Nabavizadeh $\mathrm{N}$, et al. Electromagnetic navigational bronchoscopy-guided fiducial markers for lung stereotactic body radiation therapy: analysis of safety, feasibility, and interfraction stability. J Bronchology Interv Pulmonol. 2014;21(2):123-30

26. Eberhardt $\mathrm{R}$, et al. LungPoint--a new approach to peripheral lesions. J Thorac Oncol. 2010;5(10):1559-63.

27. Al-Jaghbeer $\mathrm{M}$, et al. Diagnostic yield of electromagnetic navigational bronchoscopy. Ther Adv Respir Dis. 2016;10(4):295-9.

28. Gildea TR, et al. Electromagnetic navigation diagnostic bronchoscopy: a prospective study. Am J Respir Crit Care Med. 2006;174(9):982-9.

29. Lamprecht $B$, et al. Electromagnetic navigation bronchoscopy (ENB): increasing diagnostic yield. Respir Med. 2012;106(5):710-5.

30. Karnak D, et al. Rapid on-site evaluation and low registration error enhance the success of electromagnetic navigation bronchoscopy. Ann Thorac Med. 2013;8(1):28-32.

31. Gex G, et al. Diagnostic yield and safety of electromagnetic navigation bronchoscopy for lung nodules: a systematic review and meta-analysis. Respiration. 2014:87(2):165-76.

32. Asano F, et al. Complications associated with endobronchial ultrasoundguided transbronchial needle aspiration: a nationwide survey by the Japan Society for Respiratory Endoscopy. Respir Res. 2013;14:50.

33. Eapen GA, et al. Complications, consequences, and practice patterns of endobronchial ultrasound-guided transbronchial needle aspiration: results of the AQuIRE registry. Chest. 2013;143(4):1044-53.

34. Hayama M, et al. Complications with endobronchial ultrasound with a guide sheath for the diagnosis of peripheral pulmonary lesions. Respiration. 2015;90(2):129-35.

35. Steinfort DP, et al. Pulmonologist-performed per-esophageal needle aspiration of parenchymal lung lesions using an EBUS bronchoscope: diagnostic utility and safety. J Bronchology Interv Pulmonol. 2017;24(2):117-24.

36. Chen $\mathrm{CH}$, et al. Endobronchial ultrasound changed the world of lung Cancer patients: a 11-year institutional experience. PLoS One. 2015;10(11): e0142336

37. Sayar A, et al. The incidence of hoarseness after mediastinoscopy and outcome of video-assisted versus conventional mediastinoscopy in lung cancer staging. Acta Chir Belg. 2016;116(1):23-9.

38. Turna A, et al. Video-assisted mediastinoscopic lymphadenectomy is associated with better survival than mediastinoscopy in patients with resected non-small cell lung cancer. J Thorac Cardiovasc Surg. 2013:146(4):774-80.

39. Chauhan A, et al. Cervical mediastinoscopy: re-evaluation of an old technique in era of new imaging technology. Indian J Chest Dis Allied Sci. 2012:54(3):169-73.

40. Lardinois $D$, et al. Postinduction video-mediastinoscopy is as accurate and safe as video-mediastinoscopy in patients without pretreatment for potentially operable non-small cell lung cancer. Ann Thorac Surg. 2003; 75(4):1102-6.

41. Hujala KT, Sipila Jl, Grenman R. Mediastinoscopy--its role and value today in the differential diagnosis of mediastinal pathology. Acta Oncol. 2001:40(1):79-82.

42. Puhakka HJ. Complications of mediastinoscopy. J Laryngol Otol. 1989; 103(3):312-5.

43. Cho JH, et al. A comparative analysis of video-assisted mediastinoscopy and conventional mediastinoscopy. Ann Thorac Surg. 2011:92(3):1007-11.

44. Anraku M, et al. Video-assisted mediastinoscopy compared with conventional mediastinoscopy: are we doing better? Ann Thorac Surg. 2010;89(5):1577-81. 
45. Leschber $\mathrm{G}$, et al. Does video-mediastinoscopy improve the results of conventional mediastinoscopy? Eur J Cardiothorac Surg. 2008;33(2):289-93.

46. Hammoud ZT, et al. The current role of mediastinoscopy in the evaluation of thoracic disease. J Thorac Cardiovasc Surg. 1999;1 18(5):894-9.

47. Bayarri-Lara C, et al. Circulating tumor cells identify early recurrence in patients with non-small cell lung Cancer undergoing radical resection. PLoS One. 2016;11(2):e0148659.

48. Sawabata N, et al. Perioperative circulating tumor cells in surgical patients with non-small cell lung cancer: does surgical manipulation dislodge cancer cells thus allowing them to pass into the peripheral blood? Surg Today. 2016;46(12):1402-9.

49. Zhang W, et al. Tumor-selective replication herpes simplex virus-based technology significantly improves clinical detection and prognostication of viable circulating tumor cells. Oncotarget. 2016;7(26):39768-83.

50. Chen $X$, et al. Combination of circulating tumor cells with serum carcinoembryonic antigen enhances clinical prediction of non-small cell lung cancer. PLoS One. 2015;10(5):e0126276.

51. Fiorelli $A$, et al. Circulating tumor cells in diagnosing lung Cancer: clinical and morphologic analysis. Ann Thorac Surg. 2015;99(6):1899-905.

52. Nair VS, et al. An observational study of circulating tumor cells and (18)FFDG PET uptake in patients with treatment-naive non-small cell lung cancer. PLoS One. 2013;8(7):e67733.

53. Hofman V, et al. Preoperative circulating tumor cell detection using the isolation by size of epithelial tumor cell method for patients with lung cancer is a new prognostic biomarker. Clin Cancer Res. 2011;17(4):827-35.

54. Funaki S, et al. Novel approach for detection of isolated tumor cells in pulmonary vein using negative selection method: morphological classification and clinical implications. Eur J Cardiothorac Surg. 2011:40(2):322-7.

55. Franco $R$, et al. CXCL12-binding receptors expression in non-small cell lung cancer relates to tumoral microvascular density and CXCR4 positive circulating tumoral cells in lung draining venous blood. Eur I Cardiothorac Surg. 2012;41(2):368-75.

56. Hofman V, et al. Detection of circulating tumor cells as a prognostic factor in patients undergoing radical surgery for non-small-cell lung carcinoma: comparison of the efficacy of the CellSearch Assay and the isolation by size of epithelial tumor cell method. Int J Cancer. 2011;129(7):1651-60.

57. Yoon SO, et al. TTF-1 mRNA-positive circulating tumor cells in the peripheral blood predict poor prognosis in surgically resected non-small cell lung cancer patients. Lung Cancer. 2011;71(2):209-16.

58. Tanaka F, et al. Circulating tumor cell as a diagnostic marker in primary lung cancer. Clin Cancer Res. 2009;15(22):6980-6.

59. Liu L, et al. Detection of circulating cancer cells in lung cancer patients with a panel of marker genes. Biochem Biophys Res Commun. 2008;372(4):756-60

60. Yie SM, et al. Clinical significance of detecting survivin-expressing circulating cancer cells in patients with non-small cell lung cancer. Lung Cancer. 2009; 63(2):284-90.

61. Sawabata N, et al. Circulating tumor cells in peripheral blood caused by surgical manipulation of non-small-cell lung cancer: pilot study using an immunocytology method. Gen Thorac Cardiovasc Surg. 2007;55(5):189-92.

62. Sheu CC, et al. Development of a membrane array-based multimarker assay for detection of circulating cancer cells in patients with non-small cell lung cancer. Int J Cancer. 2006;119(6):1419-26.

63. Rolle A, et al. Increase in number of circulating disseminated epithelial cells after surgery for non-small cell lung cancer monitored by MAINTRAC(R) is a predictor for relapse: a preliminary report. World J Surg Oncol. 2005;3(1):18.

64. Yamashita J, et al. Preoperative evidence of circulating tumor cells by means of reverse transcriptase-polymerase chain reaction for carcinoembryonic antigen messenger RNA is an independent predictor of survival in non-small cell lung cancer: a prospective study. I Thorac Cardiovasc Surg. 2002;124(2):299-305.

65. Yamashita Jl, et al. Detection of circulating tumor cells in patients with nonsmall cell lung cancer undergoing lobectomy by video-assisted thoracic surgery: a potential hazard for intraoperative hematogenous tumor cell dissemination. J Thorac Cardiovasc Surg. 2000;119(5):899-905.

66. Brownback KR, et al. Electromagnetic navigational bronchoscopy in the diagnosis of lung lesions. J Bronchology Interv Pulmonol. 2012;19(2):91-7.

67. Cerfolio RJ, et al. The true false negative rates of esophageal and endobronchial ultrasound in the staging of mediastinal lymph nodes in patients with non-small cell lung cancer. Ann Thorac Surg. 2010;90(2):427-34.

Ready to submit your research? Choose BMC and benefit from:

- fast, convenient online submission

- thorough peer review by experienced researchers in your field

- rapid publication on acceptance

- support for research data, including large and complex data types

- gold Open Access which fosters wider collaboration and increased citations

- maximum visibility for your research: over $100 \mathrm{M}$ website views per year

At BMC, research is always in progress.

Learn more biomedcentral.com/submissions 